\title{
Grain Boundary Chemistry Before and After Ion Implantation in ODS Steels
}

\author{
E.A. Marquis, ${ }^{*}$ S. Lozano-Perez*, V. de Castro * \\ * Department of Materials, University of Oxford, Oxford OX1 3PH, U.K.
}

Reduced-activation (RA) oxide dispersion strengthened (ODS) ferritic/martensitic steels (FM) are potential candidate materials for structural components in fusion reactors for their improved mechanical properties over the austenitic steels, higher operating temperatures, resistance to swelling and helium embrittlement [1]. The complex microstructure of RAFM steels provides a high density of lattice defects allowing for the absorption of point defects created by irradiation and the accumulated damage is less than in conventional steels. However, the detailed behaviour of microstructural features and grain boundaries (GB) in particular in the ODS alloys is still unclear. During irradiation, a non-equilibrium $\mathrm{Cr}$ segregation profile can develop as a result of enhanced diffusion in austenitic steels, either by a vacancy or interstitial mechanism [2]. In more complex steels such as ODS steels, RIS and/or RID are expected to take place as well, but the synergies resulting from complex microstructures (nano-oxide particles, carbide phases, small grain size, alloying elements) which possibly lead to more complex behaviours under irradiation need to be clarified.

The limited knowledge of $\mathrm{Cr}$ depletion at grain boundary arises from the experimental difficulties in both controlling implantation conditions and in analyzing grain boundaries as threedimensional structures. The combination of atom probe tomography analyses and analytical electron microscopy provide unprecedented information of the 3D character of grain boundary chemistry.

A model ODS Fe-12 wt.\% Cr steel containing 0.4 wt. $\% \mathrm{Y}_{2} \mathrm{O}_{3}$ was processed by mechanical alloying followed by hot isostatic pressing (HIP) as described in [5]. The alloy was thermally annealed at $750^{\circ} \mathrm{C}$ for 4 hours. Ion implantation at temperatures between 300 and $500^{\circ} \mathrm{C}$ was performed at the EPSRC Ion Beam Center of Surrey University. Fe ions of $2 \mathrm{MeV}$ and $0.5 \mathrm{MeV}$ energy respectively were implanted with doses of $1.10^{15} / \mathrm{cm}^{2}$ and $5.10^{14} / \mathrm{cm}^{2}$ respectively to create a flat damage profile over $\sim 750 \mathrm{~nm}$. Atom-probe tomography samples were prepared by standard electropolishing methods. Atom-probe analyses at 30K were performed using a LEAP-3000X and $3000 \mathrm{HR}$ using laser pulses with a spot size of $\sim 10 \mu \mathrm{m}$ and energy of $0.4 \mathrm{~nJ}$ at $200 \mathrm{kHz}$ repetition rate. TEM samples from flat implanted surfaces were prepared using a Focused Ion Beam lift-out technique. TEM characterization and electron energy loss spectroscopy (EELS) analyses were carried out in a JEOL $3000 \mathrm{~F}$ scanning-transmission electron microscope operated at $300 \mathrm{kV}$ and equipped with a high angle annular dark field detector (HAADF) and a Gatan image filter.

Segregation of $\mathrm{Cr}$ to grain boundaries is observed in the as-HIPed state and after annealing at $750^{\circ} \mathrm{C}$ (Fig. 1). Carbon is also found at some grain boundaries. Both $\mathrm{Cr}$ segregation and complete depletion were observed after heavy-ion implantation (Fig. 2). Depletion occurs over 3-10nm at the grain boundaries. The effect of temperature and dose will be discussed.

References

[1] R.L. Klueh, D.S. Gelles, S. Jitsukawa, et al., J. Nuclear Mat. 307 (2002) 455-465.

[2] P.R. Okamoto and L.E. Rehn, J. Nucl. Mater. 83 (1979) 2-23.

[3] V. de Castro, T. Leguey, A. Muñoz, et al., J. Nucl. Mater. (2009), doi:10.1016/j.jnucmat. 2008.12.136. 
[4] EAM acknowledges the support of EPSRC and the Royal Society, VdC acknowledges the support of FP6 Euratom Research and Training Programme on Nuclear Energy.
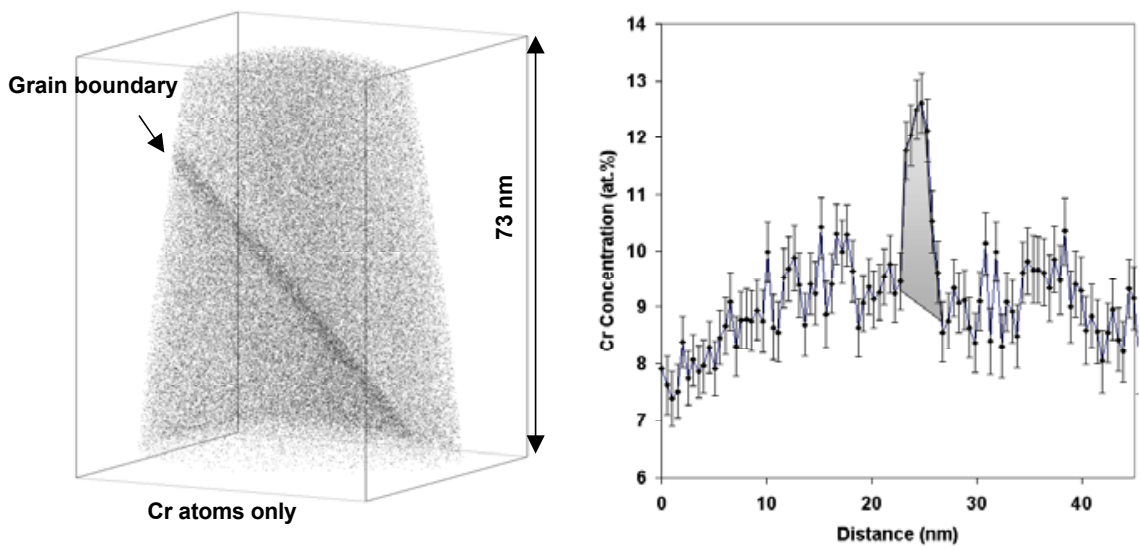

FIG 1: (a) 3D atom probe reconstruction (b) Concentration profiles across grain boundaries showing Cr segregation before irradiation.

(a)

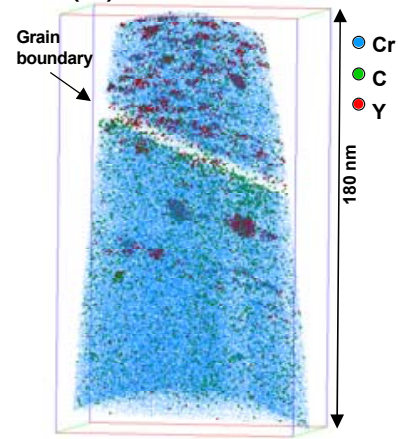

(b)

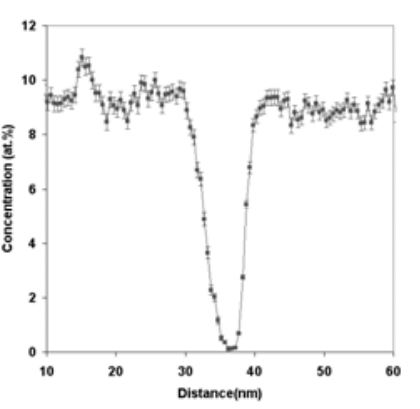

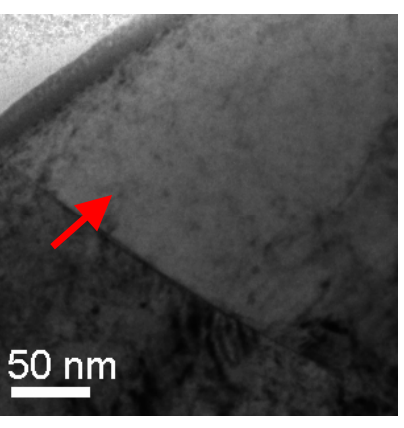

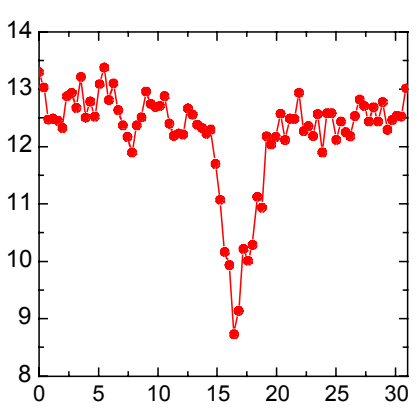

FIG 2: 3D atom probe reconstruction and concentration profile across grain boundaries showing $\mathrm{Cr}$ depletion after irradiation (b) BF-TEM image of a grain boundary located $\sim 60 \mathrm{~nm}$ from the irradiated surface, with EELS $\mathrm{Cr} \mathrm{L}_{2,3}$ relative concentration showing $\mathrm{Cr}$ depletion across the grain boundary. 